\title{
THE RUSSELLIAN THEORY OF TIME*
}

\section{NATHAN OAKLANDER}

There have been many objections raised against the Russellian theory of time. ${ }^{1}$ Recently, it has been criticized by George Schlesinger in an article entitled "Philosophical Equanimity and the Stillness of Time."2 Schlesinger's criticism is that there are certain undisputable phenomena that are completely unexplicable and unintelligible on the Russellian view, and since any adequate philosophy of time must be reconcilable with these phenomena, he concludes that the Russellian view is inadequate. Furthermore, he argues that the view of time associated with McTaggart is preferable to the Russellian view because the McTaggartian can make intelligible the undisputable phenomena in question. Schlesinger's criticism of Russell and defense of McTaggart are important and cannot be ignored by anyone who, like myself, adopts a Russellian view of time. Consequently, my task in this essay will be to provide a defense of the Russellian view that is limited to the objections that Schlesinger raises agianst it. I shall proceed by dividing the paper into two sections. In the first section I shall explain what I take the Russellian view to be and show how on it the undisputable phenomena can be understood. In the second section I shall consider Schlesinger's claim that the undisputable phenomena cannot be understood on Russell's view and attempt to show that his argument is unsound because it is based on a misunderstanding of the Russellian view.

\section{I}

The aim of Schlesinger's article is to establish that ultimately we should "have to side with McTaggart [and against Russell] and

* I wish to thank the Faculty Research and Special Projects Committee of The University of Michigan-Flint for their support and PHILOSOPHIA's anonymous referee for helpful comments on earlier drafts of this paper. 
concede that time must be moving ...." Schlesinger claims, correctly I believe, that it is an impression deeply felt by all of us that time flows relative to the present, and he thinks that this impression must be correct since it is based upon some undisputed phenomena. ${ }^{4}$ According to Schlesinger, the phenomena that are "strongly indicative" of the temporal universe having a movement from the future through the present and into the past, are our different attitudes toward events in the future and events in the past. Concerning the first set of attitudes we may note that a very painful experience that is known to have happened to us in the past, say a painful operation, is when contemplated thought of with relief. As we sometimes say, "Thank goodness that's over!" On the other hand, when we know that an equally painful operation is something that will occur in our future our attitude is one of dread and anxiety. Similarly, we often feel nostalgia over pleasant events that have happened and joy over events that we expect to happen. In both sorts of cases, there seems to be a kind of conceptual connection between the different attitudes and the nature of time. Events that are contemplated with nostalgia are not just those that are past, but they are events that are receding or moving away from us. Those that are contemplated with joy are often those that not only are in the future, but are understood as coming towards us and about to overtake us; about to be in the now, in the stream of our lived experience. Analogously our relief that a highly disagreeable experience is over is somehow conceptually connected with our belief that the experience is moving away from us and "that our feel of dread... is explained by the fact that the agonizing experience is seen to be approaching us and is known to be about to overtake us." It is such undisputable attitudes and experiences as these that provide, according to Schlesinger, strong evidence against the Russellian conception and for McTaggart's conception of time.

At the outset we may acknowledge that the difference in attitudes that Schlesinger describes do in fact exist. Moreover, I think that we must also admit that the differences in attitude imply that "time moves." But the whole question centers around what is meant by saying that "time moves." Although our attitude of dread implies that we conceive of events being first in the future and then moving toward us so that they are eventually happening to us, our attitude of dread is far from clear as to how we are to understand the "flow"of events from the future to the present. It is the task of philosophy to enable us or at least to aid us in understainding what 
is meant by time's "movement." In a passage from Russell's lectures on "The Philosophy of Logical Atomism" he says:

The process of sound philosophizing, ... consists mainly in passing from those obvious, vague, ambiguous things, that we feel quite sure of, to something precise, clear, definite, which by reflection and analysis we find is involved in the vague thing that we start from, and is, so to speak, the real truth of which that vague thing is a sort of shadow. ${ }^{6}$

If we apply Russell's views on "sound philosophizing" to the problem of time we may say that, if he knows what he is about, the Russellian need not deny the deeply felt impression that time is moving. ${ }^{7}$ Thus, he need not dispute the "undisputable phenomena" that Schlesinger employs to justify our belief in the transiency of time. But the obvious truth that time is moving, though something that we feel quite certain of is, nonetheless, vague and ambiguous. Thus, the task of philosophy is to reflect on that vague truth, and arrive at, to use Russell's phrase, "the real truth of which that vague thing is a sort of shadow." The point here is that we cannot identify our deeply entrenched belief in the movement of time with McTaggart's account of it. To believe that time moves is not ipso facto to believe that there is a special temporal particular - the "now" - that moves along a series of events, or that there are the properties of pastness, presentness, and futurity which events possess and continually change with regard to. Our deeply entrenched beliefs about time are not as sophisticated as McTaggart's view of time in whatever way we interpret it. Consequently, although our different attitudes towards the past and the future do imply that time has a trainsient aspect in some sense, they do not imply that time moves in the sense explained by McTaggart. It may be the case that time moves or has a transient aspect in the sense in which the Russellian says it does, and that gives rise to the following two questions: (1) What is the Russellian view of time, and (2) In what sense does time move or have a transient aspect, according to the Russellian view?

We will have occasion to delve more deeply into the Russellian view when we consider Schlesinger's objections to it, but for the present we may content ourselves with indicating the essential aspects of that view. The most fundamental aspect of the Russellian view is that temporal relations are simple, unanalyzable, and irreducible. As I understand the underlined words the Russellian view implies that (i) "earlier than" cannot be defined in terms of 


\section{NATHAN OAKLANDER}

"past," "present," and "future." To be able to give such a definition or reduction would show, according to one conception of philosophy, that one need not countenance temporal relations in one's ontology. Thus, the Russellian maintains that an adequate ontology of time requires temporal relations, and that temporal properties and/or temporal individuals alone will not do. The Russellian view also implies that (ii) temporal relations do not require that their relata have temporal properties. On the Russellian view $x$ can be earlier than $y$ even if it is not the case that $x$ and $y$ each have one of the temporal characteristics of pastness, presentness, or futurity. ${ }^{8}$ The Russellian view also maintains that (iii) there are no non-relational temporal properties of pastness, presentess, and futurity.

The Russellian does not deny that we truly predicate "past," "present," and "future" of events, but he maintains that that does not imply there are temporal properties named or referred to by these predicates. Indeed, he denies that such temporal properties exist and historically has offered several different analyses of temporal predicates to demonstrate this. ${ }^{9}$ The most plausible and I would say correct view is that the word "now" or "present" names a certain time. What time? The time at which the word is uttered, or written down. Thus, for example, to say that "event $e$ is now occurring" when uttered or written at time $t_{1}$ expresses the fact that the event in question is occurring at $t_{1}$, and to say that "even $e$ is now occurring" when uttered or written at $t_{2}$ expresses the fact that the event in question is occurring at $t_{2}$, and so on. Similarly, to say that "event $e$ will occur in the future" when uttered at $\mathrm{t}_{1}$ expresses the fact that the event in question occurs (tenselessly) later than $t_{1}$. Finally, to say at $\mathrm{t}_{\mathbf{1}}$ that "event $e$ has occurred in the past" when expressed at $t_{1}$ expresses the fact that the event in question occurs (tenselessly) before $t_{1}$. On the Russellian view, the nowness of events occurring at $t_{1}$ is nothing more than the time at which these events occur, namely, $t_{1}$. Nowness is not, on this view, a temporal particular that "shifts" from time to time. Nevertheless, we need not claim that our different attitudes toward the past and future are mistaken or irrational, and we need not deny the deeply held belief that time is moving from the future into the present. To see why this is so we shall turn to our second question.

In what sense, then, does time move or have a transient aspect, according to the Russellian view? How could a Russellian account for our experience of time's movement? Consider, for example, the 
event of the return of my wife, Linda, after a one month vacation in the Philippines. I have been antiticpating the event for three weeks, and now I anticipate it once more with joy. All the while I sense that her return is coming closer and closer and that eventually it will be taking place. I may describe my experience as an experience of time's moving, but what does that mean? On the Russellian view, a plausible answer would be the following: There is a certain event $e$ (Linda's retum to the U.S.) that occurs (tenselessly) at $t_{n}$. At say $t_{1}$, I wish it was now $t_{n}$ or I say to my friend, "I am looking forward to Linda's return at $t_{n}$." Then, at a later time $t_{2}$, I wish and say the same thing. Finally, suppose, at $\mathrm{t}_{\mathrm{n}}$ (the time at which event $e$ occurs (tenselessly) I experience the joy that I have been anticipating. The Russellian would say, as would everyone else, that time (event $e$ ) moved from the future to the present. The truth that underlies that vague statement would, however, be the following: My wish or utterance occurs (tenselessly) at $t_{1}$ and the event that $I$ wish to occur is later than $t_{1}$. At $t_{2}$, my wish or utterance occurs (tenselessly), but the temporal span (duration) between $t_{2}$ and $t_{n}$ is less than the temporal span between $t_{1}$ and $t_{n}$. Finally, at $t_{n}$, the experience of joy occurs (tenselessly) and so does the event $e$ that $I$ have been anticipating at $t_{1}$ and $t_{2}$. On this account, the passage of time is reflected in the fact that different wishes or utterances occur (tenselessly) at different times and at different temporal distances from the time at which event $e$ occurs. Now, at $t_{n+1}$, I may experience nostalgia due to the "passing of the joyful event into the past" and the Russellian would unpack the kernel of truth in that phrase by saying that the experience of nostalgia occurs (tenselessly) at $t_{n+1}$ and the joyful event $e$ that I am nostalgic about occurs (tenselessly) at $t_{n}$, and $t_{n}$ is earlier than $t_{n+1}$. As the temporal distance between $t_{n}$ and now (i.e., the time referred to by the use of the word "now" in the utterance "I am now nostalgic") increases, the event $e$ may be said to recede or pass more and more into the past. Thus, on the Russellian view, there is a justification of our different attitudes towards past and future events, and more importantly, there is a clear and intelligible sense in which time has the transiency required by our deeply felt impression.

In order to get a clearer understanding of the Russellian view it will be useful to consider some arguments against the account of it just given. The first argument may be stated as follows: The series of real numbers has certainly no extra particular travelling along it but one can say that "going" along it in one direction we find the 


\section{NATHAN OAKLANDER}

numbers increasing and "going" along it in the other direction we find the numbers decreasing. So the obvious answer of McTaggart would be that similarly for the Russellian who denies the existence of a moving NOW one may speak equally well about going along the time series in one direction as in the other. Clearly seen from the other direction $t_{1}$ succeeds $t_{2}$ which succeeds $t_{3}$ which succeeds $t_{4}$ and so on. Thus, I could just as justifiably talk about being nostalgic toward $e$; all the while I sense Linda's return receding further and further into the future! Since the conclusion of this argument is absurd, if the Russellian view is committed to it, then the Russellian view must be rejected. Fortunately, the argument is either invalid, unsound, or question begging.

A key premise in the first argument is that "for the Russellian who denies the existence of a moving NOW one may speak equally well about going along the time series in one direction as in the other." There are at least two things that the key premise could mean: (1) It could mean that on the Russellian view if $A$ is earlier than $B$, then $B$ is later than $A$, or (2) It could mean that on the Russellian view if $\mathbf{A}$ is earlier than $B$ it could still be the case that $B$ is earlier than A. If we interpret the key premise as (1), then it is true but it does not entail that I may be nostalgic about an event in the future. If we interpret the key premise as (2) then the first argument is valid, but it rests upon a premise that is either false or question-begging. To see what is involved in this last point let us turn to the ontological issue surrounding the "direction" of time.

One way of understainding the ontological issue surrounding the "direction" of time is to put it in the context of what constitutes the difference between space and time. There is a peculiar difference between spatial and temporal relations that Broad once expressed in a passage worth quoting at length:

The peculiarity of a series of events in Time is that it has not only an intrinsic order but also an intrinsic sense. Three points on a line have an intrinsic order, i.e., $B$ is between $A$ and $C$, or $C$ is between $B$ and $A$, or $A$ is between $C$ and $B$. This order is independent of any tacit reference to something traversing the line in a certain direction. By difference in sense I mean the sort of difference which there is between, say, $A B C$ and CBA. Now points on a straight line do not have an intrinsic sense. A sense is only assigned to them by correlation with the left and right hands of an imaginary observer, or by thinking of a moving body traversing the line in such a way that its presence 
at $\mathrm{A}$ is earlier than its presence at $\mathrm{B}$, and the latter is earlier than its presence at $C^{10}$

For Broad it would be nonsense to suppose that a temporal series could be going in one direction as well as the other since what distinguishes the temporal series from a spatial series is that only the former is a series of events that have an intrinsic sense or direction without tacit reference to some "imaginary observer" or "moving body." $M$. Black refers to the same distinction between space and time when he says that,

time is not "isotropic," in the way that we have seen space to be,... It does indeed seem that the meaning of the claim that A happened earlier than B does not depend upon the speaker's position or point of view - or on the point of view of anybody or anything else. It seems to me nonsensical to suggest that if $A$ is earlier than $B$, it might after all still be the case that B is earlier than $A .^{11}$

It is, however, precisely that suggestion that the first argument makes against the Russellian view. Thus, on the only interpretation that would make the first argument valid, the crucial premise is false and hence the argument is unsound.

Since there is the distinction between space and time that Broad and Black discuss, questions arise as to tis ontological basis or explanation: "What in reality are the truth conditions for the direction or intrinsic sense of time?" Alternatively, "What is the difference between a spatial and a temporal series?" By briefly considering these questions we can see in what way the first argument is question begging. For the Russellian the direction of time is wholly constituted by the unique asymmetrical relation of succession. The appeal to a simple temporal relation to give time a direction or sense is one and only one of several possible ontological explanations of the direction of time. McTaggart spoke of the fundamental feature of time as being constituted by the changing of events with respect to the characteristics of pastness, presentness, and futurity. For Broad, the crucial feature of a temporal series is that events in it acquire temporal relations through the continual increase in the sum total of existence.$^{12}$ For S. McCall the crucial feature of time is in the progressive discarding of those possible worlds which do not become actual. ${ }^{13}$ In short, there are numerous accounts of the ontological ground of the direction of time, i.e., of the ontological basis of the distinction between space and time. All views that maintain that without a special kind of change there 


\section{NATHAN OAKLANDER}

would be no temporal relations (nor a temporal series) are views that maintain that becoming is absolute. Absolute becoming in its various disguises are different ways of accounting for the direction of time that are anti-Russellian. Thus, if one claims that without absolute becoming there is no direction to time, then one would also claim that on the Russellian view there is no direction to time. In other words, the argument is that since the Russellian view spatializes time we may speak of time as going in one direction as well as in the other, and consequently we may be nostalgic over events in the future. Such an argument is, however one that begs the question for it assumes that the Russellian view spatializes time in a literal and pernicious sense because it does not ground the direction of time in absolute becoming.

That the direction of time is founded upon absolute becoming is an essential tenet of McTaggart and other so-called A-theorists, and is nicely stated by Broad in the following passage.

It seems to me that there is an irreducibly characteristic feature of time, which I have called "Absolute Becoming." It must be sharply distinguished from qualitative change, though there is no doubt a connection between the two. In the experience of a conscious being Absolute Becoming manifests itself as the continual supersession of what was the latest phase by a new phase, which will in turn be superseded by another new one. This seems to be the rock-bottom peculiarity of time, distinguishing temporal sequence from all other instances of one-dimensional order, such as that of points on a line, numbers in order of magnitude, and so on. ${ }^{14}$

Clearly, from the A-theorists point of view, without absolute becoming in some form or another there would not be a temporal series, but a series indistinguishable from a spatial one. Yet a McTaggartian cannot assume that central tenet in an argument against Russell without assuming what needs to be porved. The A-theory thesis that on the Russellian view time is essentially like space, is at the core of Schlesinger's argument against the Russellian view, but before we return to that let us consider another objection to our statement of it.

The second argument against my account of the Russellian view is even more important then the first since it goes to what is perhaps the central point of Schlesinger's paper. It may be stated as follows: Because of strong psychological reasons an impression may have been formed in my mind that there is a tiger outside my house and consequently I dread to open the door. But as soon as I am reasoned 
with and it is clearly demonstrated to me that there is no tiger anywhere within miles of my house I shall - if I am rational - overcome my fear. Now, it may be argued that my account of the Russellian view succeeds in explaining how according to Russell the impression of the movement of time arises even though in objective reality there is no temporal particular that actually moves. Nevertheless, I would still leave unexplained why an enlightened person upon realizing that his dread of a terrible event in the future relentlessly "coming" or "moving" toward him is merely an impression, since in fact nothing dreadful is really approaching him, does not succeed in overcoming his dread.

As in the first argument, the above argument contains a crucial, but ambiguous premise, namely, that on the Russellian view, there is no objective "coming" or "moving" of future events toward us and that nothing dreadful is really "approaching" us. That premise may mean (as the critic seems to intend it to mean) (1) that on the Russellian view there is no temporal particular that moves along the temporal series or more generally, that there is no absolute becoming. Or, it may mean (2) that for the Russellian there is no objective basis whatsoever for the movement of time; that on the Russellian view time does not have an intrinsic sense. If we interpret the crucial premise in the second sense, then the second argument is valid: it would be irrational for us to fear or dread certain "future" events, and it would leave unexplained the reason for our irrational fear. However, the second interpretation is either false or question begging. It is false since the Rusellian need not deny either that events move toward us or that time has an intrinsic sense (direction). For the Rusellian events do move and time does have an intrinsic sense and the basis of these facts about reality is that there exists a genuine temporal relation of succession that obtains between events. On the other hand, if the critic maintains that "time moves" or has an intrinsic sense if and only if there is a temporal particular, the "now," that actually moves (or some other version of absolute becoming), then he is begging the question against the Russellian. The second argument fares no better if we take the crucial premise to be interpreted as (1), because then the argument is invalid. It is true that the Russellian denies that becoming is absolute, but it does not follow that an enlightened person who believes that McTaggart's analysis of time's movement is wrong would be irrational to continue to dread some future event that he believes is coming toward him. When one is rationally convinced that a terrible event is not coming toward him in the sense that there is a temporal 
particular that is actually moving toward him (or some other version of absolute becoming), it is still understandable why he might still fear the event. For, the person might realize that there is another (Russellian) way in which an event may come toward him. What the Russellian view claims to demonstrate is not that it is irrational to believe in the objective reality of "becoming" but that it is irrational to believe that becoming is absolute, e.g., that in objective reality there is a temporal particular that actually moves. The irrationality of that belief is not, however, to be identified with the irrationality of the belief that events are approaching us or becoming.

Finally, we may understanding the flaw of the second argument against the Russellian by noting that there is a basic and fundamental disanalogy between the two situations described in it. In the spatial case there is an impression of dread with no objective bases and hence once the person involved knows that there is no objective basis for his fear, it is irrational for him to persist with it. In the case of time, however, it is not on the Russellian view irrational to continue to fear a future dreadful event even after I have been convinced that there are some obscure metaphysical senses (absolute becoming) in which it is not moving toward me. To make the case of time analogous with space one would have to construct a case in which the dreadful event was believed to immediately follow one's anticipation of it, but that in objective reality it was either much later than the anticipation of it or earlier than the anticipation of it (because say the event in question happened already, but was forgotten). Then, once a person was informed of either of these alternatives, he would, if he is rational, overcome his fear of the event. At this point, unfortunately for the critic, the argument against Russell breaks down. For there is no reason to suppose that the person would not succeed in overcoming his fear once it is shown to be irrational. Of course, the person may still dread the event, just like the person may still fear the tiger (knowing that it is miles away), but it is not incumbent upon a philosopher to explain such irrational beliefs, and it is certainly no objection to the Russellian theory of time that people sometimes have them.

If the two arguments just considered against the Russellian view 


\section{RUSSELLIAN THEORY OF TIME}

are unsuccessful, and the Russellian account of the passage of time is intelligible, then Schlesinger is mistaken when he claims that our different attitudes of joy and relief, and dread and nostalgia are evidence for McTaggart's view of time and evidence against Russell's view of time. A question that remains, however, is why Schlesinger made the mistake? We can best answer that question by considering Schlesinger's objections to the Russellian view and uncovering the confusions upon which they are based.

\section{II}

Schlesinger's first main claim against the Russellian view is that it is incompatible with the generally held belief that time is moving. He develops his criticism by first explicating Russell's view. He says, According to Russell, there is no room for any transiency as all temporal relations between events themselves and events and moments are permanent and no temporal particular changes its fixed position in the temporal series of moments. ${ }^{15}$

McTaggart's view, on the other hand, is compatible with the belief that time is moving and for that reason is preferable to Russell's. In characterizing the McTaggartian view he says,

According to McTaggart, however, it is possible to look upon the 'now' as a particular which shifts its position relative to the series of events in the direction of the future. This movement is manifested by the fact that at one stage it is a fact that $E_{1}$ is in the future which means that $E_{1}$ is a point in time which is later than the time at which the 'now' is situated. Yet at another stage it ceases to be a fact and the 'now' reaches the same position in time at which $E_{1}$ [is] situated and the two are simultaneous; then of course, it becomes true that $E_{1}$ is in the present. ${ }^{16}$

On Russell's view there is no temporal particular - the "now" which shifts its position relative to the series of events, and consequently Russell believes that McTaggart's view is mistaken. It does not follow, however, that a Russellian must deny that the temporal universe has a transitory aspect. To deny McTaggart's view on time is not equivalent to denying the movement of time. 


\section{NATHAN OAKLANDER}

Schlesinger, however, thinks that a Russellian must deny the impression shared by all of the transiency of time, for he says,

Now while nobody denies that a deeply felt impression that time indeed flows relative to the present is a part of our mental make-up, many philosophers have already cited very strong reasons why this impression must be false. ${ }^{17}$

Schlesinger is mistaken since it is not true that philosophers of the Russellian bent have denied this deeply felt impression, but rather they have denied McTaggart's interpretation of it. Schlesinger is identifying Mc-Taggart's conception of time with our deeply felt impression about time's movement. If that is legitimate then he is correct in saying that a Russellian must deny the impression that time is moving. But to assume that it is legitimate is to beg the question against the Russellian. According to the Russellian it is perfectly rational to believe in the movement of time, what is irrational and mistaken is McTaggart's account of it.

Interestingly, Schlesinger recounts several of the standard, but nonetheless strong arguments against McTaggart's understanding of the movement of time. Yet, because he identifies McTaggart's view of time with our deeply entrenched impression concerning time's motion, and since his is unwilling to give up the impression that time moves, he is unwilling to give up McTaggart's understanding of it. As Schlesinger says in the following passage:

[I] $t$ is conceivable that we should be forced to acknowledge that moments and events have certain features which are essentially features of particulars that partake in motion. In that case we should have to side with McTaggart and concede that time must be moving even though the movement in question must be a very peculiar one, very unsimilar to movement in general or one which we cannot even hope ever completely to understand. So what we have to ask ourselves is whether this deeply entrenched impression concerning time's motion is soundly based on some undisputed phenomenon. ${ }^{18}$

The undisputable phenomena that Schlesinger uses to support our impression of time's movement and hence McTaggart's view are our different attitudes toward the past and the future. It is these 
different attitudes that form the basis of Schlesinger's second argument against the Russellian view.

Schlesinger correctly notes that our attitude of relief towards a painful experience that is over and anxiety toward a painful experience that is yet to come can be explained only if we suppose that time is moving from the future into the present and from the present into the past. He goes on to say,

But it is only according to McTaggart that it is legitimate to think of events as engaged in the process of moving toward or away from the present. As we have already said, according to Russell time is essentially like space in which all relations are fixed. If it is given that I have a painful experience at a spot which is one mile to my left and also one at a spot which is one mile to my right, from this we cannot derive that there must be a difference in my attitude toward these two experiences. The spatial relations of these two relations are symmetrical with respect to my position and knowing them alone does not warrant that I should be concerned more by the one than by the other. Similarly, when an unpleasant experience occurs at a given temporal distance from the time at which this token occurs, why should it matter which direction this experience lies? ${ }^{19}$

The overriding argument is that since Russell's view cannot account for, justify, or explain our different attitudes towards the future and the past, whereas McTaggart's view can, it follows that McTaggart's view is preferable to Russell's. The argument is unsound because it is based upon the ultimately unacceptable premise that according to Russell, time is essentially like space. To see why this premise is ultimately unacceptable we must turn to a closer examination of Schlesinger's account of the dispute between Russell and McTaggart on the nature of time.

According to Schlesinger, the dispute between McTaggart and Russell is essentially an ontological one, for it concerns the nature of temporal relations. Schlesinger says,

There are basically two different views on the nature of temporal relations that exist; one is due to McTaggart, the other to Russell. According to McTaggart, temporal particulars possess, in addition to the commonly agreed relations, some 


\section{NATHAN OAKLANDER}

very special ones, while Russell denies this. The opponents of Russell regard his temporal universe as essentially impoverished while Russellians hold that their opponents admit into their universe nonexistent properties. ${ }^{20}$

According to Schlesinger, McTaggart and the Russellian's agree that temporal particulars possess the temporal relations of earlier than, later than, and simultaneous with. The very special ones that MćTaggart affirms and Russell denies are those that obtain between the "now" or the "moving present" and the series of events generated by the commonly agreed relations. On McTaggart's view, the same event is, at different times, earlier than, later than, and simultaneous with the "now." For Russell, however, the "now" does not exist and consequently, there are no changing temporal relations. ${ }^{21}$

Schlesinger also characterizes the controversy concerning temporal relations in terms of the different kinds of temporal statements that exist. He says that both views agree that some temporal statements are B-statements, that is statements which "if true at any time [are] true at all times, and if false at any time [are] false at all times," 22 e.g., "P is earlier than Q." The disagreement is over Astatements, that is, statements that change their truth value, e.g., "P is present." McTaggart argues that time and change require A-statements and Russell argues that time and change do not require them. On Russell's view, the putative A-statement "P is present" is no more than an abbreviation of the B-statement "P is (tenselessly) simultaneous with this token" or if uttered at $t_{1}$, that "P is (tenselessly) at $t_{1} . "$

Thus, on Schlesinger's interpretation, there is a basic disagreement and a basic agreement between McTaggart and Russell. They disagree over the status of the "now" and the changing relations generated by its "movement," and they agree that B-statements express facts about temporal relations between and among particulars. It seems to me, however, that the disagreement between Russell and McTaggart is much deeper and fundamental than Schlesinger's characterization would lead us to believe. The dispute is ultimately over what Schlesinger infelicitously calls "the commonly agreed relations." According to the Russellian, temporal relations between particulars are unanalyzable and irreducible to non-relational properties possessed by the particulars so related. 
According to McTaggart, however, temporal relations are reducible and analyzable in terms of non-relational properties. In other words, Russell affirms and McTaggart denies that there are temporal relations in the ontological sense. As we shall see, not only McTaggart's writings, but paradoxically, some of Schlesinger's other writings on time also support my interpretation of the Russell-McTaggart dispute.

Let us begin by considering some of McTaggart's remarks concerning the nature of temporal relations. At the beginning of his discussion of time in The Nature of Existence, McTaggart notes that positions in time appear prima facie to form two series. They form an A series, i.e., "that series of positions which runs from the far past ... to the present, and then from the present, through ... to the far future," ${ }^{23}$ and they also form a B series, i.e., "the series of positions which runs from earlier to later, or conversely." ${ }^{24} \mathrm{He}$ also notes that we usually contemplate time by the help of a metaphor of spatial movement. Either we take "the B series as sliding along a fixed A series," or we take "the A series as sliding along a fixed B series." 25 It is claims such as these that lead some commentators to hold that McTaggart construes time as involving both temporal relations and temporal properties. But there are other claims that he makes that cast serious doubt upon that interpretation. Consider the following where McTaggart says that "the distinction between past, present, and future is ... more fundamental than the distinction of earlier and later."26 I submit, that to say that temporal properties are more "fundamental" than temporal relations means, for McTaggart, that temporal relations are analyzable in terms of temporal properties, but not vice versa. To put McTaggart's point linguistically, we may say that the fundamental nature of temporal properties reveals itself in that the Bexpression "earlier than" may be defined in terms of Aexpressions like "past," "present," and "future," but that Aexpressions cannot be defined in terms of Bexpressions. Indeed, McTaggart offers a definition of "earlier than" when he says that "the term $P$ is earlier than the term $Q$, if it is ever past while $Q$ is present, or present while $Q$ is future."27

The linguistic point concerning the definability of "earlier than" has ontological implications. McTaggart argues that there cannot be a B series without an A series. The thrust of his argument is that if 


\section{NATHAN OAKLANDER}

we remove the A series from time, then there cannot be a series of events standing in temporal relations because it is the A series, or more accurately, a series of A series, that "makes" or "generates" a $B$ series out of a non-temporal series. In other words, on McTaggart's view, the only transitive asymmetrical relations that exist are nontemporal, and it is the becoming of events, that is, the changing of events from being in the future, to being in the present, to being in the past, that generates temporal relations. In short, on McTaggart's view, there are no simple, unanalyzable temporal relations. There is some clear textual evidence that bears out my interpretation. He says,

The meridian of Greenwich passes through a series of degrees of latitude. And we can find two points in this series, $S$ and $S^{\prime}$, such that the proposition "at $S$ the meridian of Greenwich is within the United Kingdom" is true, while the proposition at $S^{\prime}$ the meridian of Greenwich is within the United Kingdom is false. But no one would say that this gave us change. Why should we say so in the case of the other series [i.e., the B series]?

Of course there is a satisfactory answer to this question if we are correct in speaking of the other series as a time-series. For where there is time, there is change. But then the whole question is whether it is a time-series. My contention is that if we remove that $A$ series from the prima facie nature of time, we are left with a series which is not temporal, and which allows of change no more than the series of latitudes does. ${ }^{28}$ Precisely the same point is made in a later passage:

... the series of earlier and later is a time series. We cannot have time without change, and the only possible change is from future to present, and from present to past. Thus until the terms are taken as passing from present to past, they cannot be taken as in time, or as earlier and later ...29

Thus, although McTaggart speaks of a B series, it does not exist ontologically. My interpretation of McTaggart is given more credence by noting that it coincides with Broad's interpretation in his Examination of McTaggart's Philosophy. Broad says that McTaggart's view might be put most clearly and fairly as follows:

There is a set of terms such that at any moment every A- 
characteristic belongs to one or other of them, each of them has one and only one A-characteristic, and no two of them have the same A-characteristic. Each of these terms changes perpetually in respect of its A-characteristic in the direction from greater to less futurity, through presentness, to greater and greater pastness. These changes are so adjusted that the algebraical difference between the A-characteristics of any two terms remains constant and independent of the absolute values of their A-characteristics. To say that $X$ is "so much earlier than" $Y$ at any moment means simply and solely that the algebraic difference between the A-characteristics of $X$ and of $Y$ is so-and-so at that moment. Since this algebraical difference is constant, $\mathrm{X}$ will be exactly as much earlier than $\mathrm{Y}$ at every moment as it is at any moment. ${ }^{30}$

McTaggart asserts the fundamental nature of the $A$ series and claims that temporal relations are definable in terms of it. In a recent article we find that Schlesinger agrees with McTaggart's analysis of temporal relations and attempts to vindicate it. He argues that 'B-statements, e.g., 'P is earlier than Q' are in fact definable in terms of a disjunction of A-statements along the lines McTaggart has suggested." We shall consider his definition later, but now let us note that Schlesinger views himself as vindicating McTaggart by providing an adequate definition or reduction of B-statements. Since, however, to define or reduce a B-statement in terms of a disjunction of A-statements might be interpreted (as Broad and I have done) as ontologically eliminating temporal relations, it follows that Schlesinger might have construed McTaggart as attempting to eliminate Russellian temporal relations from the ontological nature of time. If he did, then his interpretation is correct since for McTaggart there are no unanalyzable temporal relations. Where Schlesinger goes radically wrong is in supposing that Russell and McTaggart partially agree concerning the ontological nature of time.

One may object to my interpretation of McTaggart and thus to my criticism of Schlesinger's account of the Russell-McTaggart dispute by claiming that McTaggart did not intend to ontologically eliminate temporal relations in terms of temporal properties, but rather to establish only that unanalyzable temporal relations are dependent upon changing temporal properties. In other words, 
McTaggart and Schlesinger in offering definitions of "earlier than" could be asserting that temporal relations are irreducible and unanalyzable, but that without absolute becoming (e.g., changing A-characteristics, the moving now, and so on), temporal relations cannot exist. This weaker alternative is Broad's own view in his Examination and he states it nicely in the following passage:

Even if we reject the view that " $X$ is earlier than $Y$ " means that there is a difference in the A-characteristics of $X$ and $Y$ and that this difference is positive, there remains another alternative which would suffice for McTaggart's purpose. It might be suggested that the relation "earlier than" can hold only between terms which have A-characteristics; just as harmonic relations can hold only between terms which have pitch ... In fact, to use an expression of Meinong's, we might be able to see that B-relations are "founded upon" differences in the A-characteristics of the related terms.

This view seems to me to be a highly plausible one, and I know of no positive argument against it. If it were accepted, we should have to grant to McTaggart that there could not be B-relations between terms unless the terms had A-characterstics, even if we refused to admit that B-relations are definable in terms of A-characteristics and their differences. ${ }^{32}$

The weaker interpretation of McTaggart and the official view of several other A-theorists is that both Russellian temporal relations and non-relational temporal properties exist, but I shall argue that McTaggart and other A-theorists cannot consistently admit Russellian temporal relations into their ontology. In other words, McTaggart and Russell do not agree on the ontological status of temporal relations.

We may begin to see what is involved by noting that McTaggart and other A-theorists differ from Russellians on the fundamental issue of what it is for something to exist. ${ }^{33}$ For the A-theorists, "to exist" means "to be present." Since what is not present or not happening now does not exist, it follows that for the A-theorists, the past no longer exists and the future does not yet exist. The Russellian, on the other hand, denies that existence is a tensed notion. For him all events ("past," "present," and "future") and everything else that is, exists tenselessly. In other words, "present- 
ness does not confer any kind of ontological distinction upon events." 34 These different accounts of existence lead to different accounts of temporal relations: The Russellian maintains that temporal relations are descriptive relations since they obtain if and only if their relata exist. Since, however, on the A-theory only the present exists, it follows that what succeeds or precedes the present does not exist. Thus, for the A-theorist, the temporal "relation" of succession is a peculiar, atypical relation that can connect what exists with what does not exist. Indeed, since two events in the past (future) may be such that one is followed by the other, it follows that on the A-theory, temporal relations can obtain between events that do not exist. ${ }^{35}$ Consequently, since the Russellian theory of temporal relations implies that the relata of temporal relations must exist, and the A-theory implies that temporal "relations" can connect existents with nonexistents, it follows that Russellian temporal relations are ontologically different from McTaggart's. In short, for McTaggart, there are no Russellian temporal relations.

It is of no avail to suggest that McTaggart thought that the past, present, and future exist in the Russellian tenseless sense. For if we say that then either there is, for McTaggart, no "genuine change" and hence no temporal relations, or there is "genuine change" with tenseless existence (that is, events change from existing (tenselessly) in the future, to existing (tenselessly) in the present, to existing (tenselessly) in the past), and that leads to a contradiction. ${ }^{36}$ In either case, there are no Russellian temporal relations. Thus, the basic disagreement between Russell and McTaggart is whether there are simple and unanalyzable temporal relations or whether temporal relations are generated by the movement of the "now." In this context a question that immediately arises is: "Why would Schlesinger mistakenly think that Russell and McTaggart even partially agree on the nature of time? "The answer to this question will lead us directly to the fundamental flaw in Schlesinger's argument against Russell and therefore is worth considering at some length.

All philosophers of time, whether they are followers of McTaggart or Russell, agree that time necessarily involves temporal relations, but not all philosophers agree that statements that describe a temporal relation between two events, i.e., B-statements, are "time- 


\section{NATHAN OAKLANDER}

lessly," "eternally," permanently," or "always" true or false. For example, during one stage in his musings on time, Broad maintained that before an event comes into existence it does not have any temporal relations to anything since he claimed that the future does not exist, and what does not exist cannot be a relatum of any relations including temporal relations. ${ }^{37}$ For Broad, after an event comes into existence it joins up with the sum total of existence (the past and the present) and becomes later than past events and remains later than those events forever after. Thus, for Broad, a statement such as "P is earlier than Q" is neither true nor false at the time when $P$ is present and $Q$ is future, but it becomes true and remains true thereafter when $Q$ comes into existence. On the other hand, Russell and McTaggart both agree that statements describing temporal relations between events are "timelessly," or "permanently," etc., true or false. But even though they completely agree concerning the "permanent" and "unchanging" truth value of B-statements it does not follow that they even partially agree concerning the ontological nature of time. To see once more why this is so we must attend to an ambiguity in the notions of "permanently," "timelessly," "eternally," and "always" true or false.

At first glance, to say that a statement has a "permanent" or "unchanging" etc., truth value has a reasonably clear meaning. It means that the sentence used to make it is true (or false) whenever or at every time it is uttered or written. But what could be the basis or condition for a statement being true at every time? There are at least two possibilities: Suppose we adopt the Augustinian hypothesis and assume that before God created the heaven and the earth there was no time. ${ }^{38}$ Suppose further that the heaven and the earth will persist throughout all of time. That is, suppose the heaven and the earth are individuals that endure forever. Then, the statement that "the heavens and the earth exist" is "permanently" true or true whenever it is uttered, and the basis of its truth are individuals the earth and the heavens - that exist at every time. In other words, a statement may be "permanently ${ }_{1}$ "true meaning that there exists at every time or throughout all of history something that is the basis of its truth. Consider next another statement that is "permanently" true and has an "unchanging" truth value, namely, "Two plus two equals four." Suppose that we adopt the Russellian hypothesis and 
assume that such a truth asserts a relationship between and among universals. ${ }^{39}$ Then, although the statement is true at every time, the basis for its truth is not something that exists at every time, but rather it is something that does not exist in time at all. Its truth is based upon something, a state of affairs, that exists apart from and independently of time. Thus, by calling "Two plus two equals four" eternally $y_{2}$, timelessly ${ }_{2}$, or permanently ${ }_{2}$ true, we mean that it would be true even if time did not exist.

The distinction being alluded to can perhaps be elucidated by comparison with Chisholm's analogous distinction between states of affairs and the concretisation of states of affairs. According to Chisholm, states of affairs are abstract and eternal objects, they are connected with time only insofar as they are instantiated or concretized, that is, only insofar as they have occurrences or instances that obtain in time. Chisholm says,

... the state of affairs which is Socrates walking does not come into being when he begins to walk and doesn't cease to be when he ceases to walk. Rather, we have said it is an abstract object that exists throughout eternity. And this is entirely consistent with saying that it occurs at certain times and places and fails to occur at other times and places. ${ }^{40}$ To "exist throught eternity" is an ambiguous phrase. It can mean either to "exist at every time," or "exist apart from time." Since to exist at every time would necessitate obtaining at or occurring at every time, it is clear that Chisholm does not intend the state of affairs that Socrates walks to be eternal in that sense since Socrates is not always walking. Thus, we may conclude that for Chisholm, "to exist throughout eternity" means to exist "timelessly" or "apart from time." It must be acknowledged, however, that on Chisholm's view a state of affairs may have instances that obtain at some times and fail to obtain at others. Now, if in addition to "timeless" states of affairs, we suppose that some states of affairs may have instances that collectively "obtain throughout all of time" then we can draw a distinction between statements that are permanently true because they are about some one thing (or some series of things), that (collectively) exists at every time, and statements that are permanently ${ }_{2}$ true because they are about states of affairs that exist throughout eternity. The distinction between these two differ- 


\section{NATHAN OAKLANDER}

ent kinds of eternal or permanently true statements is crucial to a correct understanding of the complete disagreement between the Russellian and the McTaggartian view of time.

According to my interpretation, Russell and McTaggart both agree that, say, "The death of Plato is earlier than the death of Aristotle" is permanently true B-statement. They would however, disagree concerning the kind of B-statement it is because they would disagree about the nature of the state of affairs that is its truth maker. For the Russellian, B-statements more closer resemble eternally $y_{2}$ true statements then eternally ${ }_{1}$ true statements. Clearly, the B-statement is not timeless in precisely the same sense in which "Two plus two equals four" is timeless: the B-statement could not be true if time does not exist; that is, if there are no temporal relations between events. Nevertheless, it does not follow that the truth of the B-statement is based upon something that exists at every time. On the Russellian view, a true B-statement resembles a permanently $_{2}$ or eternally ${ }_{2}$ true statement in two ways. First, B-statements represent states of affairs that contain a temporal relation which is a universal that does not exist in time. In other words, a Russellian temporal relation can exist "independently" of time, which is not to assert the contradiction that temporal relations can exist even if they do not exist, but rather to say that temporal relations can and do exist even though they are not temporally related to anything. Furthermore, although the event of Plato's death and the event of Aristotle's death can be thought of as obtaining at certain times, the whole temporal state of affairs, Plato's death is earlier than Aristotle's death, like the state of affairs that two plus two equals four, neither stands in temporal realtion to anything nor obtains at certain times not obtains at everytime. Thus, for the Russellian, temporal relations are unanalyzable and B-statements represent states of affairs that more closely resemble eternal ${ }_{2}$ states of affairs than eternal ${ }_{1}$ states of affairs.

According to the McTaggartian, however, temporal relations are analyzable and the statements that express the analysis closely resemble eternal ${ }_{1}$ statements. As previously mentioned, Schlesinger himself offers a definition of a temporal relational B-statement that will explain my point. He says, 
$\mathrm{P}$ is before $\mathrm{Q}=\mathrm{P}$ is past at $t$ and $\mathrm{Q}$ is present at $t$ and $t$ is in the present or $\mathrm{P}$ is past at $t$ and $\mathrm{Q}$ is present at $t$ and $t$ is in the past or $\mathrm{P}$ is past at $t$ and $\mathrm{Q}$ is present at $t$ and $t$ is in the future. ${ }^{41}$ According to Schlesinger each of the disjuncts in the definiens are A-statements, that is, statements that change their truth value with time. But if each of the disjuncts are A-statements then the states of affairs referred to by each of the disjuncts must obtain or occur in time. In other words, there is not a single state of affairs that exists outside of the net of temporal relations or thoughout all of eternity that is the basis of " $P$ is before $Q$ " being true, but rather its basis is a state of affairs or series of such that collectively obtain throughout all of history. Thus, for McTaggart, temporal relational B-statements more closely resemble permanently ${ }_{1}$ true or false statements than permanently ${ }_{2}$ true or false statements.

This point is reinforced by noticing that on McTaggart's view it follows that there must be not only a single A series, but a sequence of A series. The argument is stated by $R$. Gale:

It can easily be shown that if there is one A-series there must be a series of A-series. Assume that the A-series consists of events $M, N$ and $O$, which are respectively past, present, and future. A past (future) event by definition is one which was (will be) present. Therefore, there was (will be) an A-series in which $M(O)$ is present. Thus, if there is one A-series there is becoming - a series of A-series. ${ }^{42}$

Thus, for Schlesinger, Gale, and other McTaggartians, B-statements such as " $P$ is earlier than $Q$ " are always ${ }_{1}$ or permanently ${ }_{1}$ true because there is at every moment an A-series that is the basis for its truth. Schlesinger by not distinguishing the two kinds of "permanently" true or false B-statements fails to recognize that although McTaggart and Russell agree that B-statements are permanent, they fundamentally disagree on their analyses of temporal relations. Schlesinger's failure to distinguish the two kinds of permanence is also at the root of his argument against Russell to which we are now ready to turn.

The key premise in Schlesinger's argument against Russell is that for Russell "time is essentially like space in which all relations are fixed." On the basis of this premise he reasons that since we would 


\section{NATHAN OAKLANDER}

not have different attitudes towards objects that are at the same spatial distance to our left or to our right, we should not have different attitudes towards experiences that are at the same temporal distance in the direction of earlier or later. The core of Schlesinger's argument can be stated slightly differently. Since spatial relations obtain among terms that exist at the same time if one thinks of space as the relations between and among places, i.e., individuals that exist at every time, then spatial relations between particulars are permanently ${ }_{1}$ fixed: they obtain between particulars that exist at every time. Further, if time is essentially like space then it is an easy step to thinking that all temporal relations between particulars are fixed in the same way as all spatial relations between places are fixed, namely, permanently, fixed. Then, since at every moment the same series of events exists in the same unchanging relations, it follows that there is no movement of time in the direction of the future to the present and so there is no justification for our different attitudes towards future and past experiences. At this juncture the McTaggartian view introduces the moving present that inexorably shifts its position along the fixed series of events toward the future and away from the past. Hence, Schlesinger claims that McTaggart's view is preferable to Russell's since it can justify our different attitudes toward the past and the future and our belief in time's move. ment, whereas Russell's view cannot justify these attitudes and beliefs.

The fundamental flaw in Schlesinger's argument is that it requires that the crucial premise ("time is essentially like space") be understood in such a way that for the Russellian "P is earlier than Q" is a permanent, B-statement, that is, a statement that is made true by something that obtains at every time. But that is not Russell's view and Schlesinger could only think it is if he confused Russell's view of temporal relations with McTaggart's. According to McTaggart, in a world without the moving present or the A series, there would not be a $B$ series, although there could still be a non-temporal series with the same logical properties as the generating relation of the B series, e.g., the series of integers. Thus, Schlesinger would be correct in maintaining that if there are two experiences at an equal "distance" from a given position in a non-temporal series, then without the movement of the "now" toward one and away from the other there 
would be no reason to care in which direction the experience lies. Nevertheless, Schlesinger cannot appeal to that truism in rejecting Russell's view since on the Russellian theory of time experiences are located in a temporal series, i.e., a series whose generating relation is earlier (later) than. Consequently, even without a moving "now" it makes all the difference in the world if at $t_{2}$, an unpleasant experience is going to occur at a later time $\left(t_{3}\right)$ or if it occurred at an earlier time $\left(t_{1}\right)$. Whether an experience takes place earlier or later than now, i.e., earlier or later than the time at which we utter the word "now," makes all the difference concerning our attitude toward it.

In support of Schlesinger's criticism of Russell's view one might reply that all he says is that time is like space in this one respect, that just as there is no special spatial particular like the "here" there is no special temporal particular like the moving "now." This is true, but from it, it does not follow that earlier than and later than are symmetrical with respect to my position in the sense that I am moving no more toward one direction than the other. At $t_{2}, I$ am moving toward the pleasant experience at $t_{3}$ and away from the unpleasant experience at $t_{1}$ because $t_{3}$ is later than $t_{2}$ and $t_{1}$ is earlier than $t_{2}$. To be sure, the movement does not involve a moving "now," but it does have a basis in reality, namely, in the simple temporal relations of earlier than and later than.

Russellians who have argued that it is completely wrong-headed to speak of time as "flowing," "moving," "marching" and the like, intend to reject Mc-Taggart's view of time or anything like it that attempts to reduce temporal relations to temporal becoming. The Russellian need not insist, as Schlesinger maintains, that "time is no more flowing in one direction than in another." ${ }^{\text {43 }}$ All he must claim is that the "flow" of time is not to be understood along the lines suggested by McTaggart or his followers. Time does move for the Russellian since events that are not now experienced by us will, at later times (later nows) be experienced by us, and those experienced events at still later times will be remembered by us, perhaps with nostalgia. It is the having of different experiences at different nows that constitutes our experience of time's movement, and it is out experience of time's movement that is the basis of our differing attitudes toward past and future events. Thus, the 


\section{NATHAN OAKLANDER}

Russellian theory of time can justify our different attitudes towards the past and the future, Schlesinger's argument notwithstanding.

Although Schlesinger's arguments do not refute the Russellian view he offers another important reason for preferring McTaggart's view over Russell's. According to Schlesinger, our attitude of relief when we contemplate an unpleasant experience that we know has happened in the past, and our attitude of dread when we contemplate an unpleasant experience that we know will happen in the future are self-explanatory on McTaggart's view. These attitudes are self-explanatory on McTaggart's view because for McTaggart "it is legitimate to think of events as engaged in the process of moving away from or toward the present." 44 But does the notion of events moving away from or toward the present really make intelligible our different attitudes toward the past and the future? The answer depends on how we are to understand the notion of "events moving." Schlesinger himself sympathetically considers some of the major objections to McTaggart's account of the movement of time. Indeed, he goes so far as to say that there are "some reasons why it is impossible to give an account of the movement of time in terms of which movement is normally understood."45 How then is the movement of time to be understood? The natural answer is that such movement is to be explained in the way in which commentators and other followers of McTaggart have explained it. Unfortunately, it is far from obvious that the alternative A-theory accounts of time's movement are any more intelligible or shed any more light on our different attitudes, than McTaggart's. For example, at one point in his career Broad understood the movement of time in terms of the "sum total of existence ... always increasing" 46 and "the everlengthening temporal order of the universe," 47 but such accounts are either circular or mistaken since they depend upon a literal and pernicious spatialization of time. Broad's later account of becoming does not elucidate the concept either for he says, "To become present is, in fact, just to become, in an absolute sense; i.e., to "come to pass" in the Biblical phraseology, or, most simply, to happen. $" 48$ Yet an appeal to the Bible does not help $m e$ in under. standing becoming. Nor do the more recent A-theory accounts of time's movement shed any more light on the concept. Gale, for. instance, concludes his book on time by saying that we cannot 
hope to understand (absolute) becoming in terms of qualitative change or any other notion since becoming is a suigeneris notion. ${ }^{49}$ But if we say that becoming is sui generis, then how does the reality of becoming make our different attitudes towards the past and the future self-explanatory? There are other A-theory accounts of time's movement although Schlesinger does not mention them, nor does he give an alternative account of how we are to understand the movement of time. Thus, it is far from evident that McTaggart's and other A-theorists talk of events moving toward or away from the present does make self-explanatory our different attitudes toward the past and the future. As we have shown, the Russellian view does offer an intelligible account of time's movement that is quite unlike McTaggart's. Thus is would appear that a careful consideration of the Russellian and the McTaggartian theories of time reveals not only that Schlesinger's arguments do not refute Russell's view, but more importantly, and contrary to what Schlesinger would have us believe, it is the Russellian view that it preferable to McTaggart's.

THE UNIVERSITY OF MICHIGAN-FLINT, FLINT, MICHIGAN 48503

USA

\section{NOTES}

I Compare, for example, C.D. Broad, "Ostensible Temporality," in The Philosophy of Time, ed. R. Gale (New York: Anchor Books, 1967), pp. 117-142. S. Cahn, Fate, Logic, and Time (New Haven: Yale University Press, 1967). F. Ferré, "Grunbaum on Temporal Becoming: A Critique," International Philosophical Quarterly, 12 (1972), pp. 426 445. R. Gale, The Language of Time (New York: Humanities Press, 1968). A.N. Prior, "Thank Goodness That's Over," Philosophy, 34 (1959), pp. 12-17. E. Sosa, "The Status of Becoming: What's Happening Now?" The Journal of Philosophy, 76 (1979), pp. 26-42. R. Taylor, Metaphysics, (2nd ed.; New Jersey: Prentice-Hall, 1974), Ch.8. G.J. Whitrow, The Natural Philosophy of Time (London: Thomas Nelson and Sons, 1961).

2 G. Schlesinger, "The Stillness of Time and Philosophical Equanimity," Philosophical Studies, 9 (1976), pp. 145-159. Hereafter referred to as "ST."

$3 \quad$ "ST," p. 153. 


\section{NATHAN OAKLANDER}

4 As we shall see; to admit that our impression that time flows is correct need not be taken as evidence for McTaggart's view. Thus, even though the undisputable phenomena do support the impression that time flows, they do not support McTaggart's view.

s "ST," p. 155.

6 B. Russell, "The Philosophy of Logical Atomism," in Logic and Knowledge, ed. R.C. March (2nd impr.; London: George Allen \& Unwin Ltd., 1964), pp. 179-180.

7 Thus, for example, D. Williams in his famous article, "The My th of Passage," in The Philosophy of Time, op. cit., pp. 98-116, says that "Time 'flows' only in the sense in which a line flows or a landscape recedes into the west.' There is passage, but it is notining extra. It is the mere happening of things, their existence strung along in the manifold" (p. 105). Cf. J. Leslie, "The Value of Time," American Philosophical Quarterly, 13 (1976), pp. 109-121.

- As evidence consider the following passage where Russell says, "I maintain that there are such facts as that $x$ has the relation $\mathrm{R}$ to $y$, and that such facts are not in general reducible to, or inferable from, a fact about $x$ only and a fact about $y$ only. They do not imply that $x$ and $y$ have any complexity, or any intrinsic property distinguishing them from a $z$ and a $w$ which do not have the relation $R$. This is what I mean when I say that relations are external." "Some Explanations in Reply to Mr. Bradley," Mind, 19 (1910), p. 374, Cf. B Russell, "On the Experience of Time," Monist, 25 (1915), pp. 212-233.

- Cf. C.D. Broad, "Time," in The Encyclopeadia of Religion and Ethics, Vol. 12, ed. J. Hastings (New York: Charles Scribner's Sons, 1922), pp. 334-335. M. Fisk, "A Prgamatic Account of the Tenses," American Philosophical Quarterly, 7 (1971), pp. 92-104. N. Goodman, The Structure of Appearance (2nd ed,; Indianapolis: The Bobbs-Merrill Company, 1966), ch. 11, sect. 2. W.V.O. Quine, Elementary Logic, (New York: Harper and Row, 1965), p.6. H. Reichenbach, Elements of Symbolic Logic, (New York: The Free Press, 1966), pp. 284-287. B. Russell, Review of Macoll's 'Symbolic Logic and Its Applications,' Mind, 15 (1906), pp. 256-257. J.J.C. Smart, "The River of Time," Mind, 58 (1949), pp. $483-494$.

10 C.D. Broad, Scientific Thought. (New Jersey: Littlefield Adams \& Co., 1959), p. 57.

1 M. Black, "The 'Direction' of Time," Analysis, 19 (1959), pp. 54-63. The quoted passage occurs on pp. 62-63.

12 As Broad says in Scientific Thought: "We have atready seen that the Time series has a definite intrinsic sense, and that this arises because 


\section{RUSSELLIAN THEORY OF TIME}

there is a continual addition to the sum total of existence, ... (p. 91). Cf. C.D. Broad, Scientific Thought, pp. 66-67.

13 S. McCall, "Temporal Flux," American Philosophical Quarterly, 3 (1966), pp. 270-281, and esp. pp. 280-281.

14 C.D. Broad, "A Reply to My Critics," in The Philosophy of C.D. Broad, ed. P.A. Schilpp (New York: Tudor Publishing Co., 1959), pp. 766.

15 "ST," p. 151.

$16 \quad$ Ibid., p. 152.

$17 \quad$ lbid., p. 152; emphasis added.

$18 \quad$ Ibid., p. 152.

$19 \quad$ Ibid., p. 156.

20 Ibid., p. 145; emphasis added. Note how Schlesinger initially characterizes the dispute as one over temporal relations, but concludes by characterizing it as one over temporal properties.

"At another place in Schlesinger's article, he holds that the dispute is no longer about relations or properties, but about what kind of particulars exist: "On the Russellian view ... all temporal relations are permanently fixed. According to McTaggart, however, it is possible to look upon the "now" as a particular which shifts its position relative to the series of events in the direction of the future" (p. 151).

22 "ST," p. 146.

23 J.M.E. McTaggart, The Nature of Existence, Vol. II, ed. C.D. Broad (Cambridge: University Press, 1927), p. 10.

24 Ibid., p. 10.

$25 \quad$ Ibid., pp. 10-11.

26 Ibid., p. 10.

27 Ibid., p. 271.

28 Ibid., p. 15; emphasis added.

29 Ibid., p. 271 ; emphasis added. Note also that the passages in which McTaggart explains what he means by saying the distinction of past, present, and future is more fundamental than that of earlier and later fit my interpretation. Cf. The Nature of Existence, p. 30.

C.D. Broad, Examination of McTaggart's Philosophy, Vol. II, Part I (New York: Octagon Books, 1976), p. 301, emphasis added.

31 G.Schlesinger, "The Reduction of B-Statements," Philosophical Quarterly, 28 (1978), pp. 162-165. The quoted passage occurs on p. 162.

32 C.D. Broad, Examination of McTaggart's Philosophy, op. cit; pp.302303.

33 Cf. A.N. Prior, Time and Modality (Oxford: University Press, 1968), pp. 26-36; Papers on Time and Tense (Oxford: University Press, 1968). 


\section{NATHAN OAKLANDER}

Papers VII and VIII; Past, Present, and Future (Oxford: University Press, 1968), ch. 8; and R. Gale, The Language of Time, op. cit., p. 103 and p. 165.

34 R.C. Hoy, "Becoming and Persons," Philosophical Studies, 34 (1978), pp. $269-280$. The quoted passage occurs on p. 269.

35 Thus, for example, Gale is committed to construing earlier than as a peculiar relation of the sort just mentioned because he claims both that (i) "temporal relations of precedence and subsequence between events are described by timelessly true or false statements," that is, "if one event is earlier than some other event by so many time-units then it is always the case that the one is so many time-units earlier than the other" and (ii) "By a past individual is meant one which existed but no longer exists and by a future individual one which will exist but does not yet exist" (The Language of Time, op. cit., pp. 7 and 9).

Cf. G. Schlesinger, "The Structure of McTaggart's Argument," The Review of Metaphysics, 24 (1971), pp. 668-677.

37 C.D. Broad, Scientific Thought, op. cit., p. 80; and The Mind and Its Place in Nature, op. cit., pp. 256-57.

38 Augustine, Confessions, BK 2, ch. 3 (London: 1951).

39 B. Russell, The Problems of Philosophy, (New York: Oxford University Press, 1978), p. 103.

40 R. Chisholm, Person and Object: A Metaphysical Study (Illinois: Open Court Pub. Co., 1977), p. 130.

4t G. Schlesinger, "The Reduction of B-Statements," op. cit., p. 165.

42 R. Gale, The Language of Time, op. cit., p. 190.

43 "ST," p. 157.

44 "ST," p. 155-56.

45 "ST," p. 153.

46 C.D. Broad, Scientific Thought, op. cit., pp. 66-67.

47 C.D. Broad, The Mind and Its Place in Nature, op. cit., p. 280. His tinal view is that we can understand becoming only if we assume that time is of at least two dimensions. Cf. "A Reply to My Critics," op. cit., pp.769772. For a critique of that gambit see my "McTaggart, Schlesinger and the Two-Dimensional Time Hypothesis," forthcoming in The Philosoph. ical Quarterly (October, 1983).

49 R. Gale, The Language of Time, op. cit., p. 242. 